\title{
Virtual Reality Application in Engineering Assembly Education: A Review
}

\author{
${ }^{1,2}$ Lai Lai Win, ${ }^{1 *}$ Faieza Abdul Aziz, ${ }^{1}$ Abdul Aziz Hairuddin, ${ }^{3}$ Lili Nurliyana Abdullah, ${ }^{4}$ Yap \\ Hwa Jen, $5^{4}$ Hideo Saito, and ${ }^{6}$ Norhisham Bin Seyajah
}

${ }^{1}$ Department of Mechanical and Manufacturing Engineering, Faculty of Engineering, Universiti Putra Malaysia, 43400 UPM Serdang, Selangor, Malaysia

${ }^{2}$ Department of Mechanical Engineering, Yangon Technological University, Gyogone, Insein, Yangon, Myanmar

${ }^{3}$ Department of Department of Multimedia, Faculty of Computer Science and Information Technology, Universiti Putra Malaysia, 43400 UPM Serdang, Selangor, Malaysia

${ }^{4}$ Department of Mechanical Engineering, Faculty of Engineering, University of Malaya, 50603 Kuala Lumpur, Malaysia

${ }^{5}$ Department of Information and Computer Science, Keio University, 3-14-1 Hiyoshi

Kohoku-Ku Yokohama, 223-8522, Japan

${ }^{6}$ Department of Engineering Technology, University Kuala Lumpur, Malaysia Italy Design

Institute (UNiKL MIDI), 119, Jalan 7/91, Taman Shamelin Perkasa, 56100 Kuala Lumpur, Wilayah Persekutuan Kuala Lumpur

\begin{abstract}
Education needs to change working life in order to improve and ensure the latest technology has been adopted to cater the new era of industrial revolution. To reach this, a technological-oriented education is required for students. In this section, Virtual Reality (VR) technology is useful to get empirical experience in tertiary education. Moreover, virtual world provides a hazard-free and explorative learning experience. This paper reviews the application of VR in engineering education. This work also covers the usage of VR application which begins with the history of VR application, reasons of VR in education, key elements for immersive VR collaboration, and types of VR systems. The input / output devices which involved in VR systems were also discussed. This paper also reviews VR systems classification and usage of VR in education systems. VR in design application was finally reviewed followed by the advantages and disadvantages of VR systems and VR hardware. The last section provides future trends and conclusion.
\end{abstract}

Keywords: Virtual Reality, Learning, Education, Interactive

\section{INTRODUCTION}

Virtual reality (VR) is an artificial environment that the user believes and accepts it as a real environment [1]. Currently, VR is a very powerful tool in learning, teaching, training, technology, science, medicine, retail, media, video games, urban design, and entertainment and so on [2].

In the technological developments, education plays a very important role. Education must respond to the changing requirements in working life. To reach this, a techno-logical-oriented teaching and learning process as well as gaining practical experience is vital for students. Furthermore, VR technologies provide empirical experience and more immersive in education [3].

All VR system composed of three distinct types: input interactive devises (sensors, trackers, and mice), output devices (HMDs, large 3D displays and force feedback arms), and VR engine (data and virtual models, interaction models, and a graphical user representation model) [4].

Virtual reality uses content that is computer generated to simulate images or content in life size and multidimensional [1]. VR also allows seemingly real 
interaction with simulated content through the use of special electronic equipment such as the VR headsets and sensors embedded in the user's clothing and so on [5]. The interactive and immersive experience accorded by virtual reality technology and the ability of VR to facilitate realistic learning activities has the potential to radically transform the education sector with its increasing adoption [6].

\section{HISTORY OF VR APPLICATION}

The use of advanced technology, virtual environments and computer-based simulators has been well established by many fields such as industry, the military, medicine, manufacturing, maintenance, assembly and education and so on [7]. J. S. Henn et al. explored interactive stereoscopic virtual reality for neurosurgical education. The platform is based on the use of a desktop personal computer and inexpensive shutter glasses approach-based neurosurgical anatomy [8].

B. Kipping et al. reduced acute pain by using VR. The VR group got distraction via an off-the-shelf VR system, a head-mounted display, joystick hand control, personal computer, and age-appropriate software games [9]. J. Goulding et al. developed a VR training environment in which pairing instructional content can motivate to get instructional goals. This prototype was applied by using the input-process-output model to specific learning outcomes in figure 1 [10].

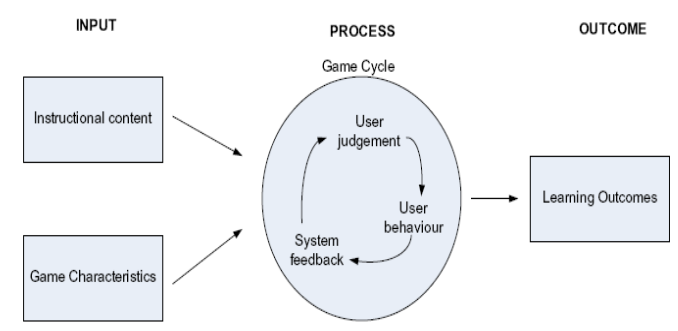

Figure 1 Instructional game model input-process-outcomes

M. W. Rohidatun et al. developed a VR system with haptic controller to enhance learning method using Personal Computer (PC). The authors also presented of an integration of Phantom Omni as device interaction in Virtual Reality system (Unity) [11], [12]. Anonymous performed usability of different natural interaction input devices in bi-manual assembly tasks of a spacecraft as shown in figure 2 . The blue shaded part shows a projection of where the part was mounted to when released [13].

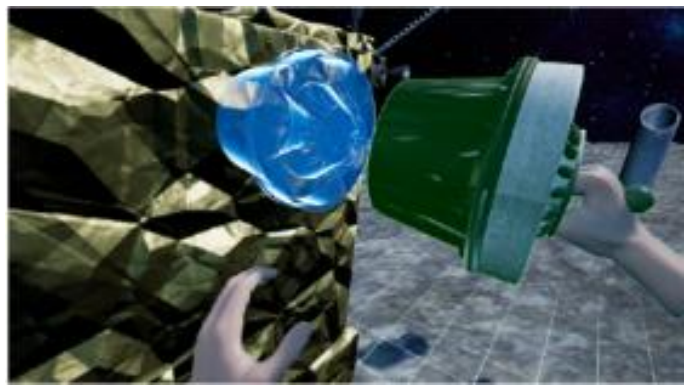

Figure 2 Bi-manual assemblies in our virtual reality environment

T. Bakker et al. developed a haptic device and proprioceptive feedback for spatial design tasks were conducting a test with tactile in use [14]. W. Fleeson et al. simulated exterior model by using computational fluid dynamics (CFD) visualization with VR [15].

A. de Giorgio et al. interacted human and machine for production engineering of VR. The virtual robot manipulator was used as an assembly task. The students controlled the movement and wore the head-mounted display and hold a controller. The robot manipulator followed the movement and allowed by its six DOF [16]. E. Matsas and G.-C. Vosniakos designed a virtual reality training system for human-robot collaboration. The robot arm was attached upside-down to a metallic. The robotic arm took a carbon patch from a workbench. When the robot moved, the user was capable seeing and hearing it [4].

The applicant can get seeing experience throughout the headset, and apply to the gyroscope by building the smartphone. As well as, the head can turn, and the sight can change in real time. T. M. Takala used a VR software development toolkit [17]. N. Gerig et al. explored missing depth cues in VR performance limit and three-dimensional reaching movement quality. The experiments were realized with an HTC Vive system driven by a desktop computer. Handheld and headmounted display were tracked with one base station as shown in figure 3 [18].

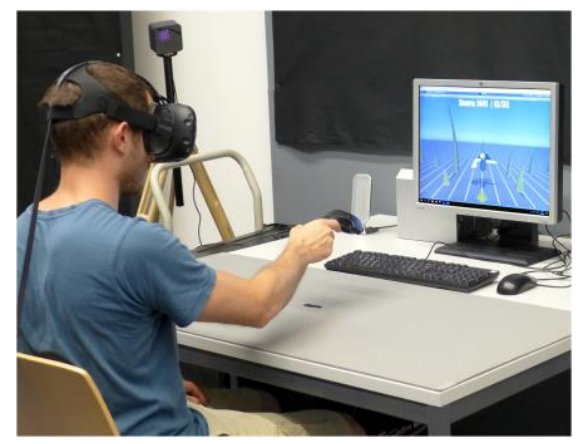

Figure 3 HTC Vive systems with a desktop computer 
A. Enrique and S. Cano designed and implemented a VR laboratory for mechanical maintenance. The scenario discussed in this paper focuses on the disassembly, bearing maintenance, and re-assembly of an $\mathrm{AC}$ motor (figure 4)[19].

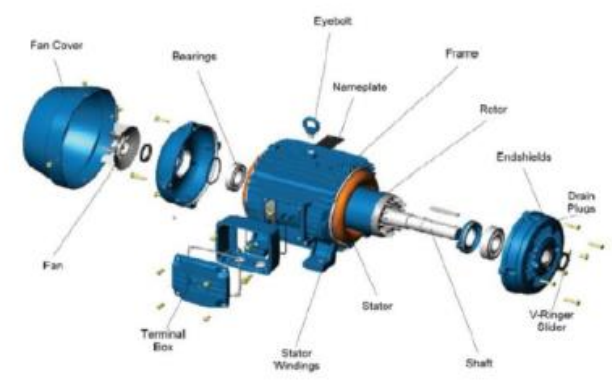

Figure 4 Motor Components

Tracing back the history of VR, the milestones were established from the 1960s (figure 4). The Aspen Movie Map provided users with simulated rides through the city of Aspen, Colorado and allowed users to choose different directions, which were considered the start of VR interaction, and in the 1980s and 1990s, VR headmounted display (HMD) and the CAVE room with projected graphics were experimented gradually [20]. Since 2000, various topics towards VR applications are blossoming, which are driving the development of VR related equipment [21].

\section{REASONS TO USE VR IN EDUCATION AND TRAINING}

Many applications have been conducted on the usage and effectiveness of VR in education since the 1980s. There are many reasons to use VR in education. In 2009, S. Veronica and Pantelidis stated that immersive VR furnishes first-person non-symbolic experiences. These experiences cannot be obtained in any other way. This kind of experience makes up our daily interaction with the world. Constructivism provides the best theory on which to develop education. The convergence of theories of knowledge construction with VR technology permits learning to be promoted [22].

\section{KEY ELEMENTS FOR AN IMMERSIVE VR COLLABORATION}

The benefit of an immersing VR is achieved by the longer attention focus interesting. For instance, a task revealed spatial learner ability positively [16]. The main factors for an immersive VR experience are listed as follows:

Immersion: It gives to the industrial operator status which involved in a virtual space [19].
Feedback: This sector provides the user experience to perform the results of their experiences in the VE [23]. Interactivity: This is the experience that can interact with the artificial environment. Sensors and devices can capture the user body activities and generate them into virtual environment. The two key elements of an immersing VR are navigation and direct manipulation [24].

Participants: Human operators are vital elements for the VR experience [25].

VR application depends on computer generated designs, that have to import VE and designs have to be navigated via input devices, and output devices generate sight, hearing, touching, and even smelling. Moreover, the applicant can get full immersion feeling in the experiment [26]. H. Zhang explored the 3I (immersion, imagination, and interaction) of VR technology in figure 5 [27].

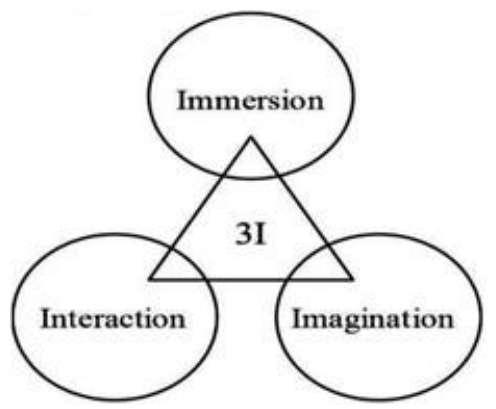

Figure 5 3I of VR

\section{TYPES OF VR SYSTEMS}

The technological advances and the growing availability of VR technology (HMD) apply the access because of their easier use [3]. There are three main categories of VR. They are non-immersive systems, semi-immersive systems, and fully immersive systems [28]. Figure 6 shows an applicant uses a "semi-immersive environment" VR system to test the machine tool.

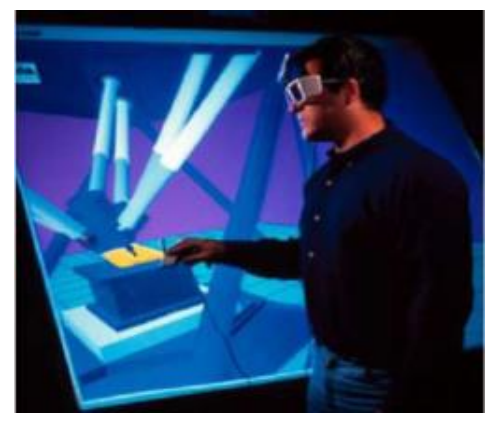

Figure 5 Virtual machine tool

Figure 7 shows a high immersive VE, which has been applied as a method for industrial design and developed to a visual and three-dimensional space [23]. 


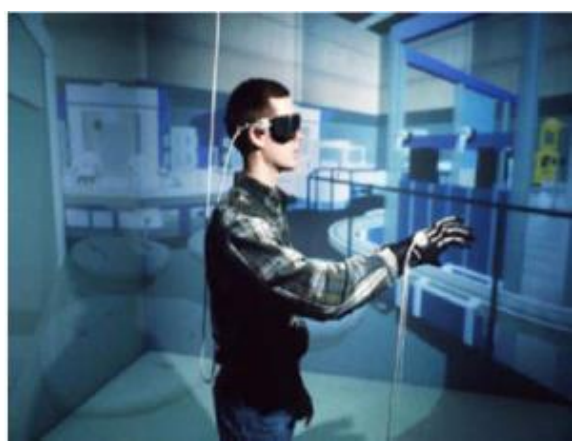

Figure 7 Fully immersive VR environments

\section{INPUT/ OUTPUT DEVICES AND CLASSIFICATION OF VR SYSTEM}

VR is very popular tool to get experimental experience, and the recent technology is $2 \mathrm{D}$ screen usage. The main difference is the current technology has a fully immersive, intuitive, and interactive experience [23] . A VR system which contained the five components namely a VR engine, software and databases, input/output devices, user, and tasks as shown in figure 8. The important VR input/output devices components are listed as below [4].

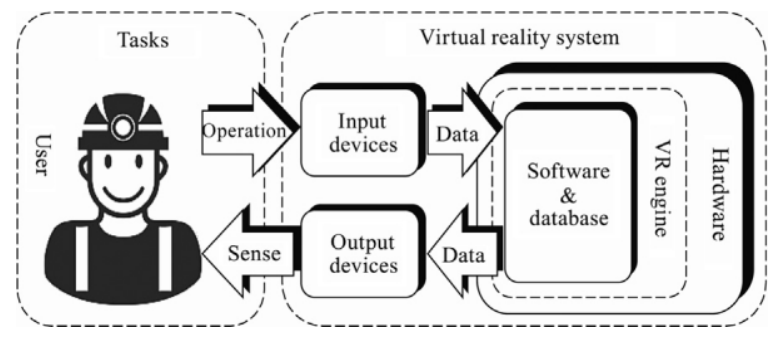

Figure 8 Components of a VR system

\subsection{Input Devices}

Depending on recent studies, the VR input devices can be classified into two kinds such as manual operation and automatic capturing. It can be seen clearly that two differences types of input devices [28] [25], [29]. They are manual operation devices and general operation devices. While general devices (keyboard and mouse) are not easy to use by beginners, the devises have a low degree of intuitive [23].

\subsection{Output Devices}

A VR education system need output devices to sense VE [15], [25]. The seeing and hearing senses play by about $70 \%$ and $20 \%$ respectively. The other three senses such as smells, touch and taste just only play 10\% (figure 9).
Therefore, visual sense plays the most important role in a VR system.

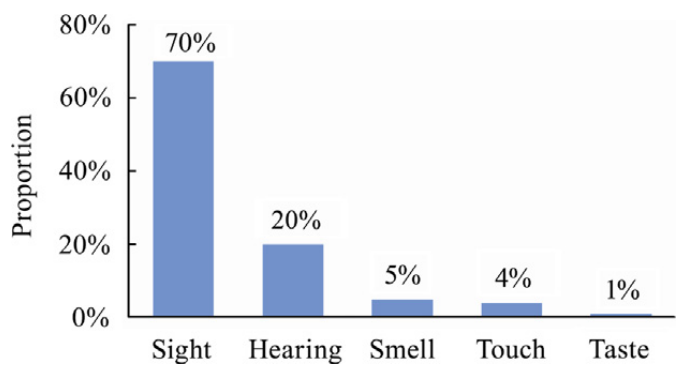

Figure 9 Contributions of the five senses

\section{VR IN EDUCATION SYSTEMS}

Depending on the classification of input/output devices, there are three types: VR system based on screen, VR system based on projector and VR system based on HMD [27]. The screen-based system applies input devices and an output device. Input devices are keyboard and joystick, and output device is desktop monitor [5][30] [31]. This system has little or no immersion. VR system based on projector is a current popular VR system. The output devices are projectors screens such as flat, multiple, curved, or domed, and so on [30]. This system also provides some immersion experiences to the users. VR system based on HMD gives the high immersive visual output devices (HMDs). In this system, the users can also feel full immersion and interaction [26].

\section{VR IN DESIGN}

VR includes creating design because it can provide the great intuitive interaction in the sight and interfacing [32]. Digital world gives the great exploring different dimensions and features by using built patterns from library, and integrates a product model [33].

VR plays a very significant rule in designing a new product [20]. Virtual design is the use of VR technology to provide the designer with a VE [14]. The advantage of design is to work with the whole team in the VE and to improve visualization of the product [28].

\section{ADVANTAGES DISADVANTAGES OF VR}

AND

Advantages of VR are creating an artificial world, more easily and comfortably, doing experiment in VE [6]. Disadvantages of VR are playing still stuck with how to interact with VE, people often live in the virtual world 
instead of dealing with the real one, VE does not have the same result as working in the real world [34].

\section{HARDWARE SYSTEMS IN VR}

VR applications require both hardware and software. But, commercial hardware devices are just also listed in this paper. The VR software must provide certain functions for the VR workshop [32]. Virtual reality is often referred to as Head Mounted Display [23]. The goal of the hardware is to create VE. [34]. In this section, hardware devices employed top VR head mounted displays in 2018 are reviewed.

Display Devices: The authors worked with the possibilities that VR technology offers to build immersive systems by using HMDs [35]. The optical see-through HMD was used instead of the video seethrough one because the video see-through one will provide a less obstructive environment for the user [36].

In general, there are six categories of displays and their degree of immersion is different such as desktop displays, head-mounted displays, arm-mounted displays, single screen displays, surround screen displays, and volumetric displays [14] [3]. Among these displays, head-mounted displays are able to provide better stereoscopic views and wearing-convenience is better [15]. Here is an overview of the top popular VR devices available on the market in 2018. There are two types of HMD like gaming VR and smartphone VR. Gaming VR HMDs are HTC vive, Oculus Rift and Sony PlayStation VR, and smartphone VR are Samsung Gear VR, Google Cardboard and Google Daydream View. We have just reviewed gaming VR HMDs.

\section{(a) HTC Vive}

HTC Vive was released in the fall of 2016 [16]. The HTC Vive uses based stations for positional tracking [37]. The Vive controllers were released together with the HTC Vive which included a multi-function tracking, a dual-stage trigger, haptic feedback, and 24 sensors. Figure 10 displays the base stations with the HMD and the controllers [38]. E.Strasnick et al. showed that the HTC Vive controllers performed best in our bi-manual assembly task and moreover, they were rated best with regard to immersion. [23]. N. Seth found several limitations in the current generation of VR and MR devices which restricts people from buying it and using it for prolong periods of time. Most of these limitations are hardware specific i.e. FOV, latency, display, etc. Certain limitations are software specific like gestures and voice in Microsoft HoloLens. Additionally, these devices are highly expensive and have limited applications available. Nonetheless, these devices have increased the scope of what humans can achieve [25]. T.
Bakker also indicated the device leads to more natural and intuitive interactions for both the point grid and vertex adjustment, but that the ergonomics needs to be improved [14].

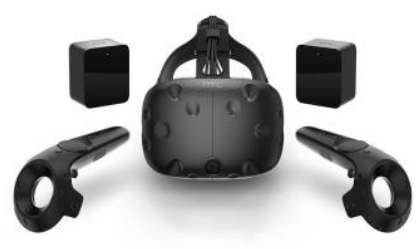

Figure 10 HTC Vive with controllers and base stations

\section{(b) Oculus Rift}

Oculus Rift was also released since 2016. [39]. Its specifications are surveyed and shown in table 1. A picture of the HMD with touch controllers is shown in figure 11 .

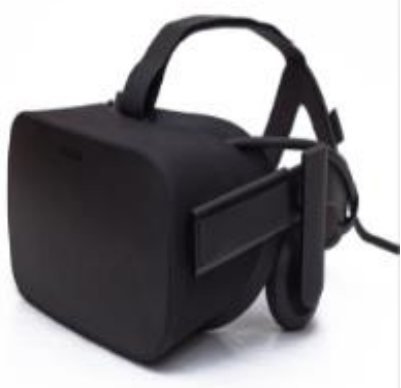

Figure 11 Oculus Rift with touch controllers

\section{(c)Sony PlayStation VR}

The PlayStation VR has a 5.7-inch OLED display with slightly lower resolution than Vive and Rift, but due to its low persistence it has the potential for less motion blur. The refresh rate is up to $120 \mathrm{~Hz}$, higher than Vive and Rift [38].

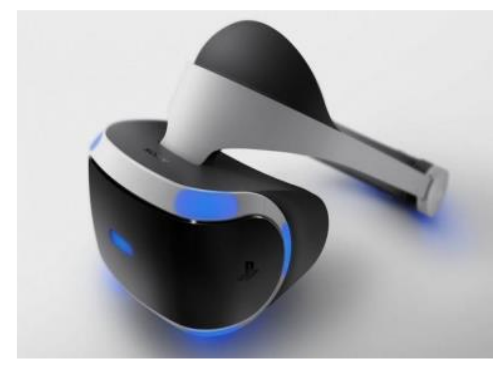

Figure 12 Sony PlayStation VR

Table 1 shows the technical details of popular VR HMDs in 2018.

Table 1 Technical detail of top VR HMDs in 2018 


\begin{tabular}{|c|c|c|c|c|}
\hline $\begin{array}{l}\text { Gaming } \\
\text { VR } \\
\text { Headset } \\
\text { Type }\end{array}$ & $\begin{array}{l}\text { Display } \\
\text { Technology }\end{array}$ & $\begin{array}{l}\text { Display } \\
\text { resolutio } \\
\text { n }\end{array}$ & $\begin{array}{l}\text { Display } \\
\text { refresh } \\
\text { rate }\end{array}$ & $\begin{array}{l}\text { Traking } \\
\text { area }\end{array}$ \\
\hline $\begin{array}{l}\text { Oculus } \\
\text { Rift }\end{array}$ & OLED & $\begin{array}{l}2160 \times 120 \\
0 \\
(1080 \times 12 \\
00 \text { per } \\
\text { eye })\end{array}$ & $90 \mathrm{~Hz}$ & $\begin{array}{l}1.5 \mathrm{~m} \mathrm{x} \\
3.4 \mathrm{~m} \\
(5.1 \mathrm{~m} 2)\end{array}$ \\
\hline $\begin{array}{l}\text { HTC } \\
\text { Vive } \\
\end{array}$ & OLED & $\begin{array}{l}2160 \times 120 \\
0 \\
(1080 \times 12 \\
00 \text { per } \\
\text { eye })\end{array}$ & $90 \mathrm{~Hz}$ & $\begin{array}{l}1.5 \mathrm{~m} \mathrm{x} \\
3.4 \mathrm{~m} \\
(5.1 \mathrm{~m} 2)\end{array}$ \\
\hline $\begin{array}{l}\frac{\text { Sony }}{\text { PlayStati }} \\
\text { on VR }\end{array}$ & OLED & $\begin{array}{l}1920 \times 108 \\
0 \\
(960 \times 108 \\
0 \text { per eye) }\end{array}$ & $90 / 120$ & $\begin{array}{l}3 \mathrm{~m} \mathrm{x} \\
1.9 \mathrm{~m} \\
(5.7 \mathrm{~m} 2)\end{array}$ \\
\hline
\end{tabular}

\section{CONCLUSIONS}

Education is very important sector in community. To be effective, teachers and students need empirical experience. In this section, VR can give not only practical experience in tertiary education to be more immersive in teaching and learning area.

This paper presents history of VR applications which are related to engineering education and emphasizes the advantages and disadvantages of VR, as well as hardware requirements of VR. The future trends of VR software will also be addressed.

\section{ACKNOWLEDGMENTS}

The project was supported by ASEAN University Network/Southeast Asia Engineering Education Development Network Project. UPM CR 1801: Vote Number: 6282000 and GIPP vot 9323709.

\section{REFERENCES}

[1] Z. Monica, "Optimization of the production process using virtual model of a workspace," IOP Conf. Ser. Mater. Sci. Eng., vol. 95, no. 1, 2015.

[2] P. A. Winkes and J. C. Aurich, "Method for an enhanced assembly planning process with systematic virtual reality inclusion," Procedia CIRP, vol. 37, pp. 152-157, 2015.

[3] D. Janssen, C. Tummel, A. Richert, and I. Isenhardt, "Virtual Environments in Higher Education - Immersion as a Key Construct for Learning 4.0," Int. J. Adv. Corp. Learn., vol. 9, no. 2, p. 20, 2016.

[4] E. Matsas and G.-C. Vosniakos, "Design of a virtual reality training system for human-robot collaboration in manufacturing tasks," Int. J. Interact. Des. Manuf., vol. 11, no. 2, pp. 139153, 2017.

[5] J. Vora, S. Nair, A. K. Gramopadhye, A. T. Duchowski, B. J. Melloy, and B. Kanki, "Using virtual reality technology for aircraft visual inspection training: Presence and comparison studies," Appl. Ergon., vol. 33, no. 6, pp. 559570, 2002.

[6] G. YILDIRIM, M. ELBAN, and S. YILDIRIM, "Analysis of Use of Virtual Reality Technologies in History Education: A Case Study," Asian J. Educ. Train., vol. 4, no. 2, pp. 62-69, 2018.

[7] R. S. Haluck, R. L. Marshall, T. M. Krummel, and M. G. Melkonian, "Are surgery training programs ready for virtual reality? A survey of program directors in general surgery," $J$. Am. Coll. Surg., vol. 193, no. 6, pp. 660-665, 2001.

[8] J. S. Henn et al., "Interactive stereoscopic virtual reality: a new tool for neurosurgical education," J. Neurosurg., vol. 96, no. 1, pp. 144-149, 2002.

[9] B. Kipping, S. Rodger, K. Miller, and R. M. Kimble, "Virtual reality for acute pain reduction in adolescents undergoing burn wound care: A prospective randomized controlled trial," Burns, vol. 38, no. 5, pp. 650-657, 2012.

[10] J. Goulding, W. Nadim, P. Petridis, and M. Alshawi, "Construction industry offsite production: A virtual reality interactive training environment prototype," Adv. Eng. Informatics, vol. 26, no. 1, pp. 103-116, 2012.

[11] M. W. Rohidatun, F. A. Aziz, R. M. Yusof, N. H. Saad, and R. Ismail, "Development of Virtual Reality ( VR ) System with Haptic Controller and Augmented Reality ( AR ) System to Enhance Learning and Training Experience .," Int. J. Appl. Eng. Res. ISSN 0973-4562, vol. 11, no. 16, pp. 8806-8809, 2016.

[12] M. W. Rohidatun, A. A. Faieza, M. Y. Rosnah, and S. N. Hayati, "Develop a virtual and augmented reality system to enhance learning and training assembly," J. Comput. Theor. Nanosci., vol. 14, no. 11, pp. 5617-5620, 2017.

[13] "Usability of Natural Interaction Input Devices in Virtual Assembly Tasks," 2017.

[14] T. Bakker, J. Verlinden, D. Abbink, and R. Van Deventer, "Development of a Haptic Device with Tactile and Proprioceptive Feedback for Spatial Design Tasks," Adjun. Proc. 2017 IEEE Int. Symp. Mix. Augment. Reality, ISMARAdjunct 2017, pp. 223-228, 2017.

[15] W. Fleeson et al., "No \{Title\}," J. Pers. Soc. Psychol., vol. 1, no. 1, pp. 1188-1197, 2017.

[16] A. de Giorgio, M. Romero, M. Onori, and L. 
Wang, "Human-machine Collaboration in Virtual Reality for Adaptive Production Engineering," Procedia Manuf., vol. 11, no. June, pp. 1279-1287, 2017.

[17] T. M. Takala, "A T o o l k i t f o r Virt u a $1 \mathrm{R}$ e a lit y S o f t w a r e D e ve lo p m e n t," no. January, 2017.

[18] N. Gerig, J. Mayo, K. Baur, F. Wittmann, R. Riener, and P. Wolf, "Missing depth cues in virtual reality limit performance and quality of three dimensional reaching movements," PLoS One, vol. 13, no. 1, pp. 1-18, 2018.

[19] A. Enrique and S. Cano, "DESIGN AND IMPLEMENTATION OF A VIRTUAL REALITY Presented to the faculty of the College of the College of Business and Technology Morehead State University In Partial Fulfillment of the Requirements for the Degree Master of Science by Adolfo Enrique Samudi," 2018.

[20] K. Smparounis, D. Mavrikios, M. Pappas, and V. Xanthakis, "A virtual and augmented reality approach to collaborative product design and demonstration," 2007.

[21] H. G. Hoffman, E. J. Seibel, T. L. Richards, T. A. Furness, D. R. Patterson, and S. R. Sharar, "Virtual Reality Helmet Display Quality Influences the Magnitude of Virtual Reality Analgesia," J. Pain, vol. 7, no. 11, pp. 843-850, 2006.

[22] V. S. Pantelidis, "Reasons to Use Virtual Reality in Education and Training Courses and a Model to Determine When to Use Virtual Reality," Themes Sci. Technol. Educ., vol. 2, no. 1-2, pp. 59-70, 2010.

[23] E. Strasnick, C. Holz, E. Ofek, M. Sinclair, and H. Benko, "Haptic Links: Bimanual Haptics for Virtual Reality Using Variable Stiffness Actuation," Proc. 2018 CHI Conf. Hum. Factors Comput. Syst. - CHI '18, pp. 1-12, 2018.

[24] M. M. Bowen, "MIDDLE-SCHOOL STUDENTS by Mary Michelle Bowen A Dissertation Submitted in Partial Fulfillment of the Requirements for the Degree of Doctor of Education Major: Instruction and Curriculum Leadership The University of Memphis May 2018," Eff. Virtual Real. Motiv. Achiev. MiddleSchool Students, no. May, 2018.

[25] N. S. Seth, "Real Time Cross Platform Collaboration Between Virtual Reality \& Mixed Reality," no. May, 2017.
[26] A. Y. C. Nee and S. K. Ong, "Virtual and augmented reality applications in manufacturing," IFAC Proc. Vol., vol. 46, no. 9, pp. 15-26, 2013.

[27] H. Zhang, "Head-mounted display-based intuitive virtual reality training system for the mining industry," Int. J. Min. Sci. Technol., vol. 27, no. 4, pp. 717-722, 2017.

[28] T. S. Mujber, T. Szecsi, and M. S. J. Hashmi, "Virtual reality applications in manufacturing process simulation," J. Mater. Process. Technol., vol. 155-156, no. 1-3, pp. 18341838, 2004.

[29] V. Computing and P. Erler, "Haptic Feedback in Room-Scale VR," 2017.

[30] T. Wischgoll, "Display Systems for Visualization and Simulation in Virtual Environments," pp. 78-88, 2017.

[31] I. Choi, E. Ofek, H. Benko, M. Sinclair, and C. Holz, "CLAW: A Multifunctional Handheld Haptic Controller for Grasping, Touching, and Triggering in Virtual Reality," 2018.

[32] H. J. Yap, Z. Taha, and H. K. Choo, "Virtual Reality-based Training System for Metal Active Gas Welding," 2014.

[33] A. Y. C. Nee and S. K. Ong, Virtual and augmented reality applications in manufacturing, vol. 46, no. 9. IFAC, 2013.

[34] V. McKalin, "Augmented Reality vs . Virtual Reality: What are the differences and similarities?," Tech Times, vol. 5, no. 6, pp. 16, 2015.

[35] I. Calvo, F. López, E. Zulueta, and P. GonzálezNalda, "Towards a methodology to build virtual reality manufacturing systems based on free open software technologies," Int. J. Interact. Des. Manuf., vol. 11, no. 3, pp. 569-580, 2017.

[36] L. Rentzos, S. Papanastasiou, N. Papakostas, and G. Chryssolouris, Augmented reality for human-based assembly: Using product and process semantics, vol. 12, no. PART 1. IFAC, 2013.

[37] O. Kreylos, "Lighthouse tracking examined." 2016.

[38] T. Lindvall and Ö. Mirtchev, "Survey of Virtual and Augmented Reality Implementations for Development of Prototype for Practical Technician Training," p. 72, 2017.

[39] C. Anthes, R. J. García-Hernández, M. Wiedemann, and D. Kranzlmüller, "State of the art of virtual reality technology," IEEE Aerosp. Conf. Proc., vol. 2016-June, no. March, 2016. 